\title{
Radiation and thermal diffusion effect on a steady MHD free convection heat and mass transfer flow past an inclined stretching sheet with Hall current and heat generation
}

\author{
Mohammad Ali ${ }^{1}$, Mohammad Shah Alam², Md. Mahmud Alam³, \\ Md. Abdul Alim ${ }^{4}$ \\ ${ }^{I}$ Assistant Professor, Mathematics, Chittagong University of Engineering \& Technology, Chittagong, Bangladesh, \\ ${ }^{2}$ Assistant Professor, Mathematics, Chittagong University of Engineering \& Technology, Chittagong, Bangladesh, \\ ${ }^{3}$ Professor, Mathematics Discipline, Khulna University, Khulna, Bangladesh \\ ${ }^{4}$ Professor, Mathematics, Bangladesh University of Engineering \& Technology, Dhaka, Bangladesh
}

\begin{abstract}
In the present paper is an investigation of steady MHD free convection, heat and mass transfer flow of an incompressible electrically conducting fluid past an inclined stretching sheet under the influence of an applied uniform magnetic field with Hall current and radiation effect. Using suitable similarity transformations the governing fundamental boundary layer equations are transformed to a system of non-linear similar ordinary differential equations for momentum, thermal energy and concentration equations which are then solved numerically by the shooting method along with Runge-Kutta fourth-fifth order integration scheme. The results presented graphically illustrate that primary velocity field decrease due to increase of magnetic parameter, Angle of inclination, Dufour number, Prandtl number, Heat generation and Soret number while secondary velocity also decrease for Hall parameter. Other parameters increase the velocities of the fluid flow. Temperature field increases in the presence of Dufour number, heat generation, Schmidt number, Magnetic parameter, Grashof number \& Modified Grashof number and decreases for other parameters. Also, concentration profiles decreases for increasing the values of Dufour number, Schmidt number, Heat generation, Soret number, Grashof number \& Modified Grashof number but concentration increases for other parameters. The numerical results concerned with the primary velocity, secondary velocity, temperature and concentration profiles effects of various parameters on the flow fields are investigated and presented graphically. Also the skin friction coefficient, the local Nusselt number and the local Sherwood number are presented in Tables 1-3.
\end{abstract}

Keywords: Hall current, Heat generation, MHD, Radiation effect, Stretching Sheet.

\section{INTRODUCTION}

In recent years MHD flow problems have become in view of its significant applications in industrial manufacturing processes such as plasma studies, petroleum industries Magneto-hydrodynamics power generator cooling of Nuclear reactors, boundary layer control in aerodynamics. The effects of magnetic field on free convective flows are of importance in liquid metals, electrolytes, and ionized gases. Due to presence of a strong magnetic field the conduction mechanism in ionized gases is different from that in a metallic substance. An electric current in ionized gases is generally carried out by electrons which undergo successive collisions with other charged or neutral particles. However, in the presence of a strong electric field, the electrical conductivity is affected by a magnetic field. Indeed, MHD laminar boundary layer behavior over a stretching surface is a significant type of flow having considerable practical applications in chemical engineering, electrochemistry and polymer processing. The numerical simulation of combined radiation and convection transport processes plays a very significant role in the area of radiative heat transfer. It is evident that the radiation effect is important under many non-isothermal situations. If the entire system involving the polymer extrusion process is placed in a thermally controlled environment, then radiation could become important. The knowledge of radiation heat transfer in the system can perhaps lead to a desired product with sought characteristic. Recently, Elbashbeshy and Bazid [1] presented an exact similarity solution for unsteady momentum and heat transfer flow whose motion is caused solely by the linear stretching of a horizontal stretching surface, Saleh M. Alharbi et.al [2] studied heat and mass transfer in MHD visco-elastic fluid flow through a porous medium over a stretching sheet with chemical reaction, M. A. Seddeek and M. S. Abdel Meguid [3] analyzed the effects of radiation and thermal diffusivity on heat transfer over a stretching surface with variable heat flux, A. A. Afify [4] discussed similarity solution in MHD effects of thermal diffusion and diffusion thermo on free convective heat and mass transfer over a stretching surface considering suction or injection, Akiyama and Chang [5] numerically analyzed the influence of gray surface radiation on the convection of nonparticipating fluid in a rectangular enclosed space, Sudha Mathew, P. Raveendra Nath and N. B. V. Rama Deva Prasad [6] studied Hall effects on heat and mass transfer through a porous medium in a rotating channel with radiation, R. Kumar and K. D. Singh [7] have 
studied Mathematical modeling of Soret and hall effects on oscillatory MHD free convective flow of radiating fluid in a rotating vertical porous channel filled with porous medium. In view of the importance of radiative heat transfer , in this paper, steady MHD free convection flow of an incompressible electrically conducting fluid past an inclined stretching sheet under the influence of an applied uniform magnetic field with Hall current and heat generation is investigated. The ordinary differential equations are obtained by similarity transformations which are solved numerically using the fourth-order Runge-Kutta integration scheme along with shooting method. The results presented graphically illustrate that primary velocity field decrease due to increase of magnetic parameter, Angle of inclination, Dufour number, Prandtl number, Heat generation and Soret number while secondary velocity also decrease for Hall parameter. Other parameters increase the velocities of the fluid flow. Temperature field increases in the presence of Dufour number, heat generation, Schmidt number, Magnetic parameter, Grashof number \& Modified Grashof number and decreases for other parameters. Also, concentration profiles decreases for increasing the values of Dufour number, Schmidt number, Heat generation, Soret number, Grashof number \& Modified Grashof number but concentration increases for other parameters. The numerical results concerned with the primary velocity, secondary velocity, temperature and concentration profiles effects of various parameters on the flow fields are investigated and presented graphically. Also the skin friction coefficient, the local Nusselt number and the local Sherwood number are presented in Tables 1-3.

\section{Formulation Of The Problem And Similarity Analysis}

Let us consider steady two dimensional MHD free convection heat and mass transfer in an incompressible electrically conducting fluid past an inclined stretching sheet under the influence of an applied uniform magnetic field with Hall current and heat generation. The flow is subjected to a transverse magnetic field of strength which is assumed to be applied in the positive $y$-direction normal to the surface. The pressure gradient, body force, viscous dissipation and joule heating effects are neglected compared with effects of with internal heat source/sink. The magnetic Reynolds number of the flow is taken to be small enough, so that the induced magnetic field is negligible in comparison to the applied one and magnetic lines of the force are fixed relative to the fluid. The magnetic field $\left(B=\left(0, B_{0}, 0\right)\right)$ is strong. Using the relation $\nabla \cdot J=0$ for the current density $\mathbf{J}=\left(\mathrm{J}_{\mathrm{x}}, \mathrm{J}_{\mathrm{y}}, \mathrm{J}_{\mathrm{z}}\right)$, we obtain $\mathrm{J}_{\mathrm{y}}=$ constant. Since the plate is non-conducting, $\mathrm{J}_{\mathrm{y}}=0$ at the plate and hence $\mathrm{J}_{\mathrm{y}}$ $=0$ everywhere. The generalized Ohm's law in the absence of an electric field in the case of short circuit is of the form. $\mathrm{J}+\frac{\omega_{\mathrm{e}} \tau_{\mathrm{e}}}{\mathrm{B}_{0}}(\mathrm{~J} \times \mathrm{B})=\sigma\left[(\mathrm{q} \times \mathrm{B})+\frac{1}{\mathrm{en}_{\mathrm{e}}} \nabla \mathrm{p}_{\mathrm{e}}\right]$

Under the assumption that the electron pressure for a weakly ionized gas, as well as the thermoelectric and ionslip terms are negligible, then from above equation, we get

$$
\mathrm{J}_{\mathrm{x}}=\frac{\sigma \mathrm{B}_{0}^{2}}{\rho\left(1+\mathrm{m}^{2}\right)}(\mathrm{u}+\mathrm{mw}) \text { and } \mathrm{J}_{\mathrm{y}}=\frac{\sigma \mathrm{B}_{0}^{2}}{\rho\left(1+\mathrm{m}^{2}\right)}(\mathrm{mu}-\mathrm{w})
$$

Thus, in accordance with the above assumptions and usual boundary layer approximation, the dimensional governing equations of continuity, momentum, concentration and energy under the influence of externally imposed magnetic field with the presence of Hall current are:

Equation of continuity: $\frac{\partial \mathrm{u}}{\partial \mathrm{x}}+\frac{\partial \mathrm{u}}{\partial \mathrm{y}}=0$

Momentum equation:

$$
\begin{aligned}
& \mathrm{u} \frac{\partial \mathrm{u}}{\partial \mathrm{x}}+\mathrm{v} \frac{\partial \mathrm{u}}{\partial \mathrm{y}}=\mathrm{v} \frac{\partial^{2} \mathrm{u}}{\partial \mathrm{y}^{2}}+\mathrm{g} \beta\left(\mathrm{T}-\mathrm{T}_{\infty}\right) \cos \gamma+\mathrm{g} \beta^{*}\left(\mathrm{C}-\mathrm{C}_{\infty}\right) \cos \gamma-\frac{\sigma \mathrm{B}_{0}^{2}}{\rho\left(1+\mathrm{m}^{2}\right)}(\mathrm{u}+\mathrm{mw}) \\
& \mathrm{u} \frac{\partial \mathrm{w}}{\partial \mathrm{x}}+\mathrm{v} \frac{\partial \mathrm{w}}{\partial \mathrm{y}}=v \frac{\partial^{2} \mathrm{w}}{\partial \mathrm{y}^{2}}+\frac{\sigma \mathrm{B}_{0}^{2}}{\rho\left(1+\mathrm{m}^{2}\right)}(\mathrm{mu}-\mathrm{w})
\end{aligned}
$$

Energy Equation:

$$
\mathrm{u} \frac{\partial \mathrm{T}}{\partial \mathrm{x}}+\mathrm{v} \frac{\partial \mathrm{T}}{\partial \mathrm{y}}=\frac{\mathrm{k}}{\rho \mathrm{c}_{\mathrm{p}}} \frac{\partial^{2} \mathrm{~T}}{\partial \mathrm{y}^{2}}-\frac{\mathrm{Q}_{0}}{\rho \mathrm{c}_{\mathrm{p}}}\left(\mathrm{T}-\mathrm{T}_{\infty}\right)+\frac{\mathrm{D}_{\mathrm{m}} \mathrm{K}_{\mathrm{T}}}{\mathrm{c}_{\mathrm{s}} \mathrm{c}_{\mathrm{p}}} \frac{\partial^{2} \mathrm{c}}{\partial \mathrm{y}^{2}}-\frac{1}{\rho \mathrm{c}_{\mathrm{p}}} \frac{\partial \mathrm{q}_{\mathrm{r}}}{\partial \mathrm{y}}
$$

Concentration Equation:

$$
\mathrm{u} \frac{\partial \mathrm{c}}{\partial \mathrm{x}}+\mathrm{v} \frac{\partial \mathrm{c}}{\partial \mathrm{y}}=\mathrm{D}_{\mathrm{m}} \frac{\partial^{2} \mathrm{c}}{\partial \mathrm{y}^{2}}+\frac{\mathrm{D}_{\mathrm{m}} \mathrm{K}_{\mathrm{T}}}{\mathrm{T}_{\mathrm{m}}} \frac{\partial^{2} \mathrm{~T}}{\partial \mathrm{y}^{2}}
$$

Boundary conditions are:

$$
\mathrm{u}=b \mathrm{x}, \mathrm{v}=0, \mathrm{w}=0, \mathrm{~T}=\mathrm{T}_{\mathrm{w}}, \mathrm{C}=\mathrm{C}_{\mathrm{w}} \text { at } \mathrm{y}=0 ; \mathrm{u}=0, \mathrm{v}=0, \mathrm{~T}=\mathrm{T}_{\infty}, \mathrm{C}=\mathrm{C}_{\infty} \text { as } \mathrm{y} \rightarrow \infty
$$


By using the Rosseland approximation, we have the radiant heat flux, $q_{r}=-\frac{4 \sigma^{*}}{3 K^{*}} \frac{\partial T^{4}}{\partial y}$ where $\sigma^{*}$ is the

Stefan-Boltzman constant, $K^{*}$ is the mean absorption coefficient. Assuming that, the difference in temperature within the flow are such that $T^{4}$ can be expressed as a linear combination of the temperatures. We expand $T^{4}$ in Taylors series about $T_{\infty}$ as follows:

$\mathrm{T}^{4}=\mathrm{T}_{\infty}^{4}+4 \mathrm{~T}_{\infty}^{3}\left(\mathrm{~T}-\mathrm{T}_{\infty}\right)+6 \mathrm{~T}_{\infty}^{2}\left(\mathrm{~T}-\mathrm{T}_{\infty}\right)^{2}+\ldots \ldots \ldots$ and neglecting the higher order terms beyond the first degree

in $\left(T-T_{\infty}\right)$; we have $\mathrm{T}^{4} \approx-3 \mathrm{~T}_{\infty}^{4}+4 \mathrm{~T}_{\infty}^{3} \mathrm{~T}$. Therefore, $\mathrm{q}_{\mathrm{r}}=-\frac{16 \sigma^{*}}{3 \mathrm{~K}^{*}} \mathrm{~T}_{\infty}^{3} \frac{\partial \mathrm{T}}{\partial \mathrm{y}}$. Hence Eq.(4) becomes

$\mathrm{u} \frac{\partial \mathrm{T}}{\partial \mathrm{x}}+\mathrm{v} \frac{\partial \mathrm{T}}{\partial \mathrm{y}}=\frac{\mathrm{k}}{\rho \mathrm{c}_{\mathrm{p}}} \frac{\partial^{2} \mathrm{~T}}{\partial \mathrm{y}^{2}}-\frac{\mathrm{Q}_{0}}{\rho \mathrm{c}_{\mathrm{p}}}\left(\mathrm{T}-\mathrm{T}_{\infty}\right)+\frac{\mathrm{D}_{\mathrm{m}} \mathrm{K}_{\mathrm{T}}}{\mathrm{c}_{\mathrm{s}} \mathrm{c}_{\mathrm{p}}} \frac{\partial^{2} \mathrm{c}}{\partial \mathrm{y}^{2}}-\frac{16 \sigma^{*} T_{\infty}^{3}}{3 \rho \rho^{*} \mathrm{c}_{\mathrm{p}}} \frac{\partial^{2} T}{\partial \mathrm{y}^{2}}$

To convert the governing equations into a set of similarity equations, we introduce the following similarity transformation:

$$
\mathrm{u}=\mathrm{bx}, \mathrm{w}=\mathrm{bxg}_{0}(\eta), \eta=\mathrm{y} \sqrt{\frac{\mathrm{b}}{v}}, \psi=x \sqrt{\nu \mathrm{b} f}(\eta), \theta(\eta)=\frac{\mathrm{T}-\mathrm{T}_{\infty}}{\mathrm{T}_{\mathrm{w}}-\mathrm{T}_{\infty}}, \varphi(\eta)=\frac{\mathrm{C}-\mathrm{C}_{\infty}}{\mathrm{C}_{\mathrm{w}}-\mathrm{C}_{\infty}}, \mathrm{u}=\frac{\partial \psi}{\partial \mathrm{y}}, \mathrm{v}=-\frac{\partial \psi}{\partial \mathrm{x}}
$$

From the above transformations, the non-dimensional, nonlinear and coupled ordinary differential equations are obtained

$$
\begin{aligned}
& \mathrm{f}^{\prime \prime \prime}+\mathrm{ff}^{\prime \prime}-f^{\prime 2}+\mathrm{G}_{\mathrm{r}} \theta \cos \gamma+\mathrm{G}_{\mathrm{m}} \varphi \cos \gamma-\frac{\mathrm{M}}{1+\mathrm{m}^{2}} \mathrm{f}^{\prime}-\frac{\mathrm{Mm}}{1+\mathrm{m}^{2}} \mathrm{~g}_{\mathrm{o}}=\mathrm{O} \\
& \mathrm{g}_{0}^{\prime \prime}+\mathrm{fg}_{0}^{\prime}-g_{0}-\frac{\mathrm{M}}{1+\mathrm{m}^{2}} \mathrm{~g}_{0}+\frac{\mathrm{Mm}}{1+\mathrm{m}^{2}} \mathrm{f}^{\prime}=0 \\
& (1+\mathrm{R}) \theta^{\prime \prime}-\mathrm{P}_{\mathrm{r}} \mathrm{f} \theta^{\prime}+\mathrm{Q} \theta+\mathrm{D}_{\mathrm{f}} \varphi^{\prime \prime}=0 \\
& \varphi^{\prime \prime}+\mathrm{S}_{\mathrm{c}} \mathrm{f} \varphi^{\prime}+\mathrm{S}_{0} \theta^{\prime \prime}=0
\end{aligned}
$$

The transform boundary conditions:

$$
\begin{aligned}
& \mathrm{f}=0, \mathrm{f}^{\prime}=1, \mathrm{~g}_{0}=0, \theta=\varphi=1 \text { at } \eta=0 \\
& \mathrm{f}=\mathrm{f}^{\prime}=\mathrm{g}_{0}=\theta=\varphi=0 \text { as } \eta \rightarrow \infty
\end{aligned}
$$

\section{RESULTS AND DISCUSSION}

The system of ordinary differential equations (7)-(10) subject to the boundary conditions is solved numerically by Runge- Kutta fourth-fifth order method using symbolic software. First of all, higher order nonlinear differential equations (7) - (10) are converted into simultaneous linear differential equations of first order and they are further transformed into initial value problem by applying the shooting technique. Numerical calculation for distribution of the primary velocity, secondary velocity, temperature and concentration profiles across the boundary layer for different values of the parameters are carried out. The effects of $\mathrm{M}$ and $\mathrm{m}$ on the primary and secondary velocity profiles are shown in Fig. 1, Fig.2, Fig.5 and Fig.6. It can be clearly seen that an increase in the magnetic parameter decreases the primary velocity $(0 \leq \eta \leq 0.6)$ and increases the secondary velocity. This result agrees with the expectations, since the magnetic field exerts a retarding effect on the free convective flow. This field may control the flow characteristics, an increase in $\mathrm{M}$ results in thinning of the boundary layer. The effect of the Hall parameter has a minor increasing effect on the primary velocity, whereas the major decreasing effect on the secondary velocity. Fig.3, Fig.4, Fig.7 \& Fig.8 depicts the temperature and concentration profiles for $\mathrm{M}$ and $\mathrm{m}$. From these figure it is observed that both temperature and concentration increase for increasing values of $\mathrm{M}$ but for increasing values $\mathrm{m}$ a minor decreasing effect on temperature profile and there is no effect on concentration. The effect of $D_{f}$ and $S_{o}$ on primary velocity, temperature and concentration profiles are shown in Fig. 9- Fig.11 and Fig.33-Fig.35. It can be seen that an increase in $\mathrm{D}_{\mathrm{f}}$ both velocity and concentration decreases but noticeable increasing effect on the temperature profile. Similar case arises for the case of Soret number (Fig.33-Fig.35). In Fig. 12, Fig.13 and Fig.14 are shown the effect of angle of inclination on primary velocity, temperature and concentration profiles. It can be seen that an increase in $\gamma$ temperature profile increases and negligible increasing effects on concentration but noticeable decreasing effect on the velocity profile. For increasing the values Prandtl number results in the lowering of the average temperature within the boundary layer. Because the smaller values of $\mathrm{P}_{\mathrm{r}}$ are equivalent to an increase in the thermal conductivity of the fluid, so that for higher values of $P_{r}$ heat is able to diffuse away from the stretching sheet more rapidly. Hence, in the case of smaller values of $\mathrm{P}_{\mathrm{r}}$, the thermal boundary layer is thicker and heat 
transfer is reduced. That is temperature profile decrease which is shown in Fig. 17 but reverse trend arises in concentration profile (Fig.15) which is expected. From Fig.16 it is observed that velocity profile decreases for increasing values of Pr. Fig.20 represents the effects of $S_{c}$ on the concentration profile. It is seen that as the Schmidt number is increased, both the concentration and concentration boundary layer thickness decrease but velocity profile is increased (Fig.18). Whereas, noticeable increasing effect on the temperature profile which is shown in Fig.19. In Fig.21, Fig.22 and Fig.23 are the graphical representations of concentration profile, temperature profile and primary velocity for the different values of the radiation parameter $\mathrm{R}$ in case of stretching sheet. It is found that primary velocity and concentration increases as the radiation parameter $\mathrm{N}$ increases. Temperature decreases as thermal radiation increases (Fig. 22). This is in agreement with the physical fact that the thermal boundary layer thickness decreases with increasing $R$ which is expected. Fig.24, Fig.25 and Fig.26 represent the effect of heat generation on primary velocity, temperature and concentration profiles. From these figures it is seen that for increasing values of $\mathrm{Q}$, the primary velocity and concentration decreases whereas temperature profile increases because physically heat generation in the fluid flow will enhance thermal energy to the flow and hence for $Q>0$, temperature increasing. Fig.27-Fig.32 displays the effect of $G_{r}$ and $G_{m}$ on primary velocity, temperature and concentration profiles. For the case of different values of thermal Grashof number; the velocity profiles in the boundary layer are shown in Fig.28. As expected, it is observed that an increase in $G_{r}$ leads to increase in the values of velocity due to enhancement in buoyancy force. Here positive values of $\mathrm{G}_{\mathrm{r}}$ corresponding to cooling of the surface. Also the negligible increasing effect on temperature and negligible decreasing effects on concentration. Similar trend arises for $G_{m}$. Tables 1-3 exhibit the behavior of $f^{\prime \prime}(0), \theta^{\prime}(0)$, and $-\varphi^{\prime}(0)$, for various values of magnetic parameter, Hall parameter, Prandtl number, angle of inclination, radiation and Schmidt number. From Table- 1, it is observed that $f^{\prime \prime}(0)$ is decreased for various values of $M, \gamma$ and $P_{r}$ and increased for increasing values of $m, R$ and $S_{c}$. From Table- 2, it is observed that $\theta^{\prime}(0)$, is decreased with the increasing values of $\mathrm{m}, \mathrm{P}_{\mathrm{r}}$ and $\mathrm{R}$ but increased for increasing values of $\mathrm{M}, \mathrm{Sc}$ and $\gamma$. From Table- 3, we see that $-\varphi^{\prime}(0)$, is increased with the increase of $M, \gamma, R$ and $P_{r}$ and decreased for $S_{c}$. On the other hand there is no effect of $\mathrm{m}$ on $-\varphi^{\prime}(0)$.

\section{CONCLUSION}

In the present paper is an investigation of steady MHD free convection, heat and mass transfer flow of an incompressible electrically conducting fluid past an inclined stretching sheet under the influence of an applied uniform magnetic field with Hall current and radiation effect. The leading equations are solved numerically by the shooting method along with Runge- Kutta fourth-fifth order integration scheme. The results are presented to display the flow characteristic like velocity, temperature and concentration. In this study we have considered the salt water $\left(\mathrm{P}_{\mathrm{r}}=1.0\right)$ and hydrogen $\left(\mathrm{Sc}=0.22 \rightarrow \mathrm{H}_{2}\right)$. In this regard the following conclusions are made:

- The magnitude of velocity decreases with increasing magnetic parameter causing of Lorentz force. Similar results are found for Dofour \& Soret number, angle of inclination and heat generation, also reverse results arise for remaining parameters.

- Increase in magnetic parameter, angle of inclination, radiation, heat generation, thermal Grashof number, modified Grashof number, Dofour \& Soret number, the temperature is increased . Reverse trend arises for remaining entering parameters.

- Increase in magnetic parameter, angle of inclination and radiation the concentration increases and reverse effect arise in case of remaining parameters. 


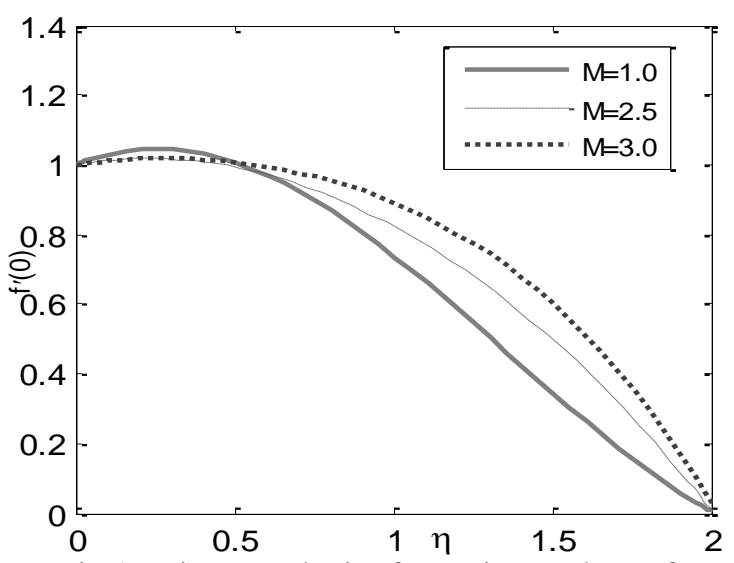

Fig.1. Primary velocity for various values of

$\mathrm{M}$ andm
$\mathrm{G}_{\mathrm{m}}=1.0, \mathrm{P}_{\mathrm{r}}=1.0, \mathrm{Q}=2.0, \mathrm{~S}_{0}=1.0, \mathrm{D}_{\mathrm{f}}=2.0, \gamma=60^{\circ}, \mathrm{G}_{\mathrm{f}}=5.0, \mathrm{~S}_{\mathrm{c}}=0.22$

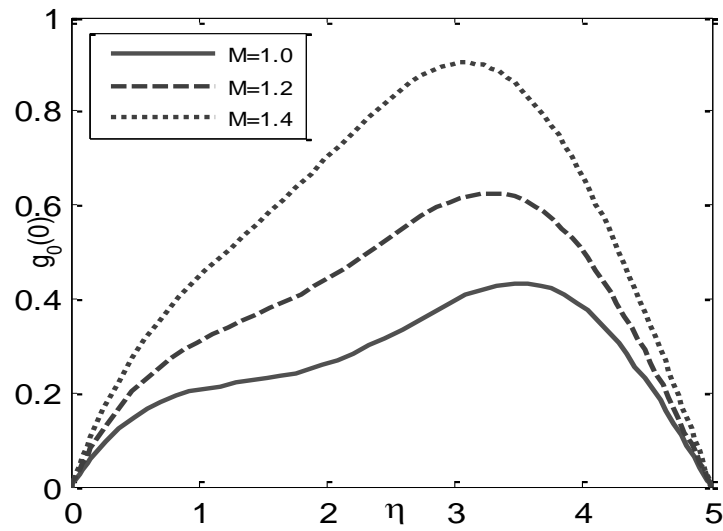

Fig.2. Secondary velocity for various values of $\mathrm{M}$ andm $=1.0, \mathrm{Q}=2.0, \mathrm{R}=2.0, \gamma=60^{\circ}, \mathrm{G}_{\mathrm{r}}=5.0$,
$\mathrm{G}_{\mathrm{m}}=1.0, \mathrm{P}_{\mathrm{r}}=1.0, \mathrm{~S}_{0}=1.0, \mathrm{D}_{\mathrm{f}}=1.0, \mathrm{~S}_{\mathrm{c}}=0.22$

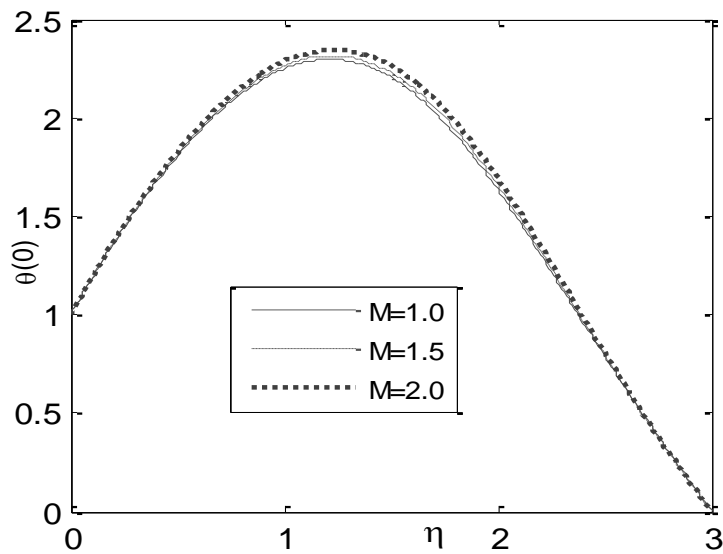

Fig.3. Temperature profile for various values of

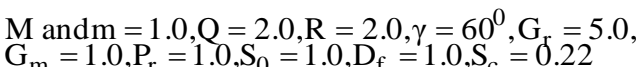

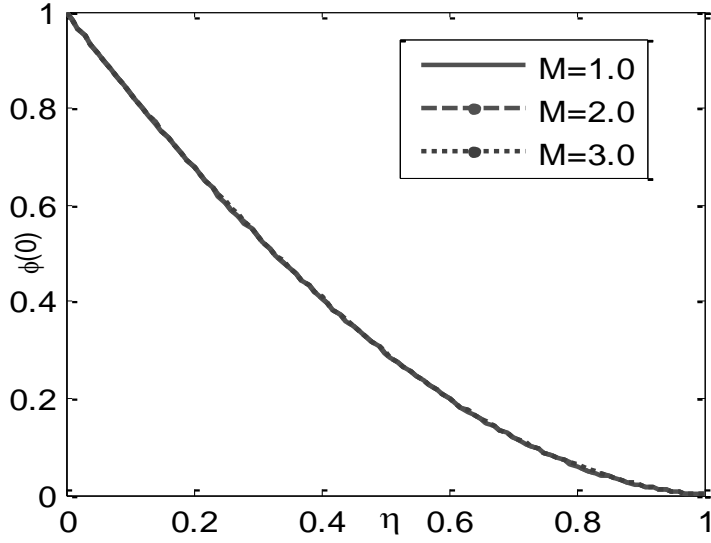

Fig.4. Concentration profile for various values of $\mathrm{M}$ andm $=1.0, \mathrm{Q}=2.0, \mathrm{R}=2.0, \gamma=60^{\circ}, \mathrm{G}_{r}=5.0$,
$\mathrm{G}_{\mathrm{m}}=1.0, \mathrm{P}_{\mathrm{r}}=1.0, \mathrm{~S}_{0}=1.0, \mathrm{D}_{\mathrm{f}}=1.0, \mathrm{~S}_{\mathrm{c}}=0.22$

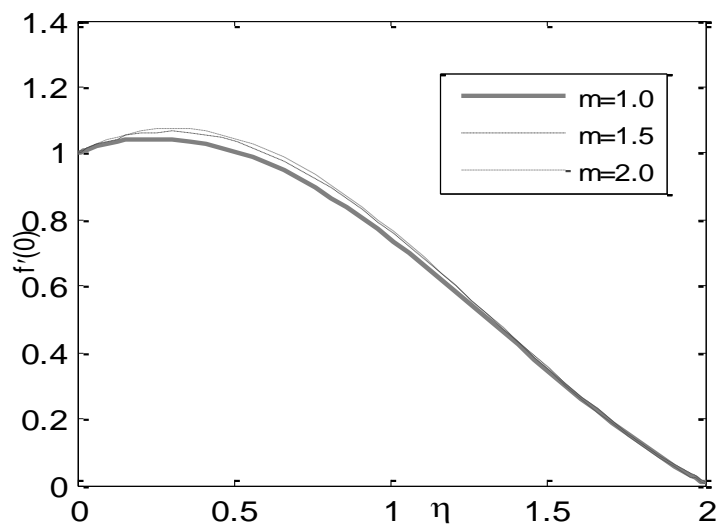

Fig.5. Primary velocity for various values of $\underset{\mathrm{G}_{\mathrm{m}}=1.0, \mathrm{P}_{\mathrm{r}}=1.0, \mathrm{~S}_{0}=1.0, \mathrm{D}_{\mathrm{f}}=1.0, \mathrm{~S}_{\mathrm{c}}=0.22}{\operatorname{and}}=1.0$,

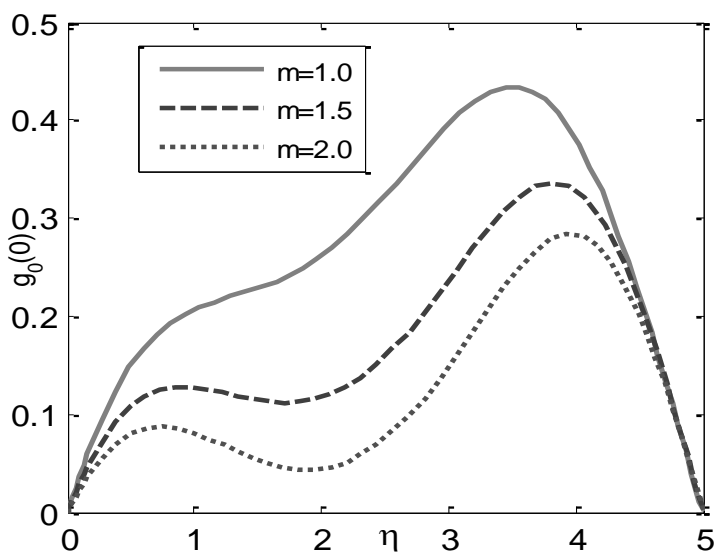

Fig.6. Secondary velocity for various values of $\underset{\mathrm{G}_{\mathrm{m}}=1.0, \mathrm{P}_{\mathrm{r}}=1.0, \mathrm{~S}_{0}=1.0, \mathrm{D}_{\mathrm{f}}=1.0, \mathrm{~S}_{\mathrm{c}}=0.22}{\operatorname{and}}=1.0$, 


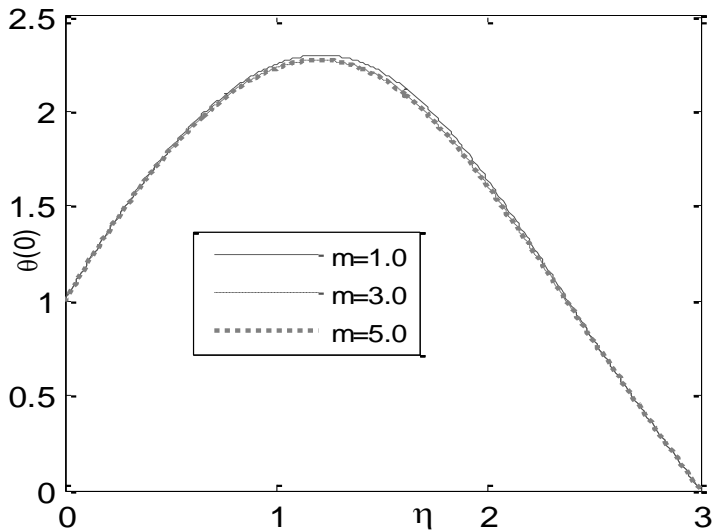

Fig.7. Temperature profile for various values of $\mathrm{m}$ and $\mathrm{M}=1.0, \mathrm{Q}=2.0, \mathrm{R}=2.0, \gamma=60^{\circ}, \mathrm{G}_{\mathrm{r}}=5.0$,
$\mathrm{G}_{\mathrm{m}}=1.0, \mathrm{P}_{\mathrm{r}}=1.0, \mathrm{~S}_{0}=1.0, \mathrm{D}_{\mathrm{f}}=1.0, \mathrm{~S}_{\mathrm{c}}=0.22$

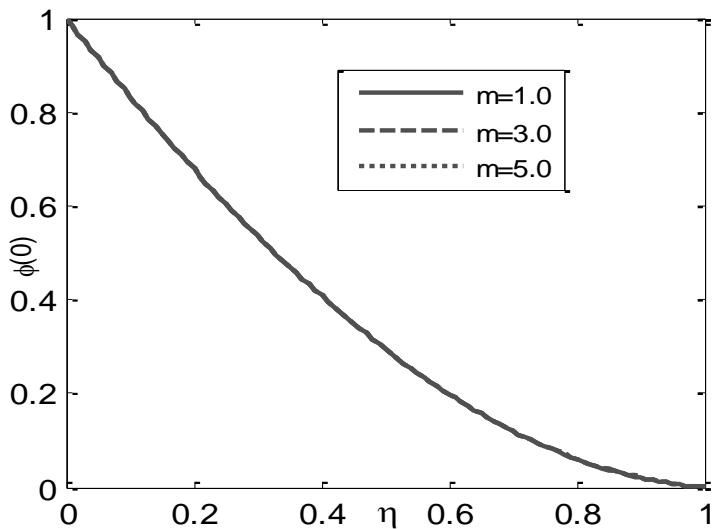

Fig.8. Concentration profile for various values of $\mathrm{m}$ and $\mathrm{M}=1.0, \mathrm{Q}=2.0, \mathrm{R}=2.0, \gamma=60^{\circ}, \mathrm{G}_{\mathrm{r}}=5.0$,
$\mathrm{G}_{\mathrm{m}}=1.0, \mathrm{P}_{\mathrm{r}}=1.0, \mathrm{~S}_{0}=1.0, \mathrm{D}_{\mathrm{f}}=1.0, \mathrm{~S}_{\mathrm{c}}=0.22$

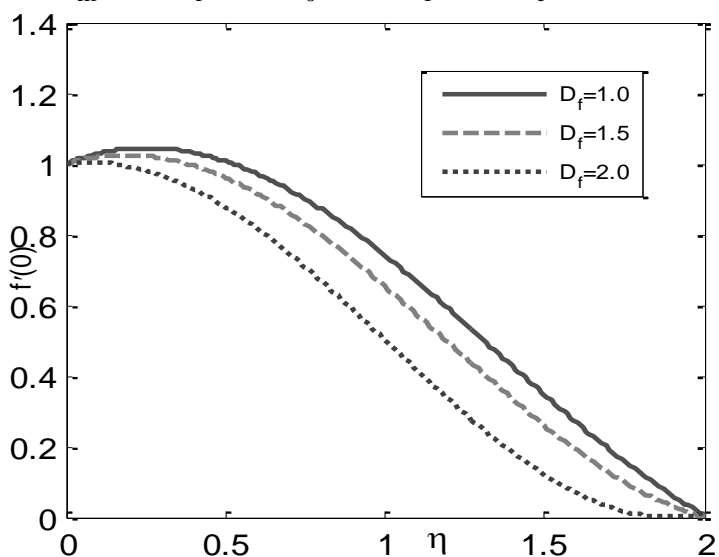

Fig.9. Primary velocity for various values of $\mathrm{D}_{\mathrm{f}}$ andM $=1.0, \mathrm{Q}=2.0, \mathrm{R}=2.0, \gamma=60^{0}, \mathrm{G}_{\mathrm{r}}=5.0$,
$\mathrm{G}_{\mathrm{m}}=1.0, \mathrm{P}_{\mathrm{r}}=1.0, \mathrm{~S}_{0}=1.0, \mathrm{~m}=1.0, \mathrm{~S}_{\mathrm{c}}=0.22$

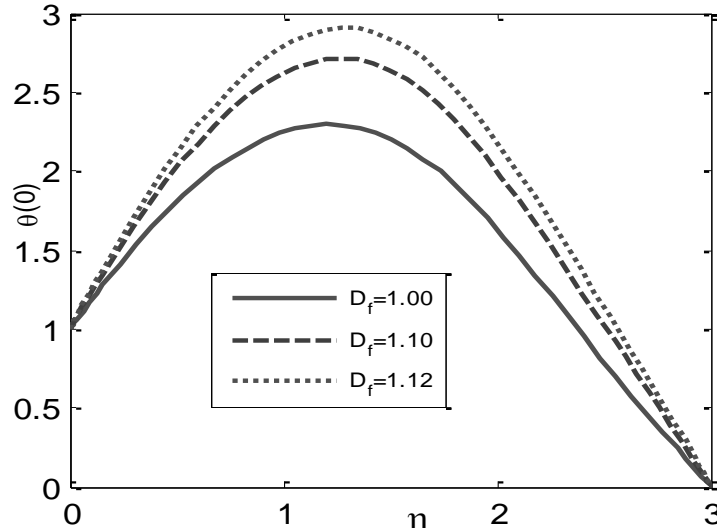

Fig.10. Temperature profile for various values of $\mathrm{D}_{\mathrm{f}}$ andM $=1.0, \mathrm{Q}=2.0, \mathrm{R}=2.0, \gamma=60^{0}, \mathrm{G}_{\mathrm{d}}=5.0$,
$\mathrm{G}_{\mathrm{m}}=1.0, \mathrm{P}_{\mathrm{r}}=1.0, \mathrm{~S}_{0}=1.0, \mathrm{~m}=1.0, \mathrm{~S}_{\mathrm{c}}=0.22$

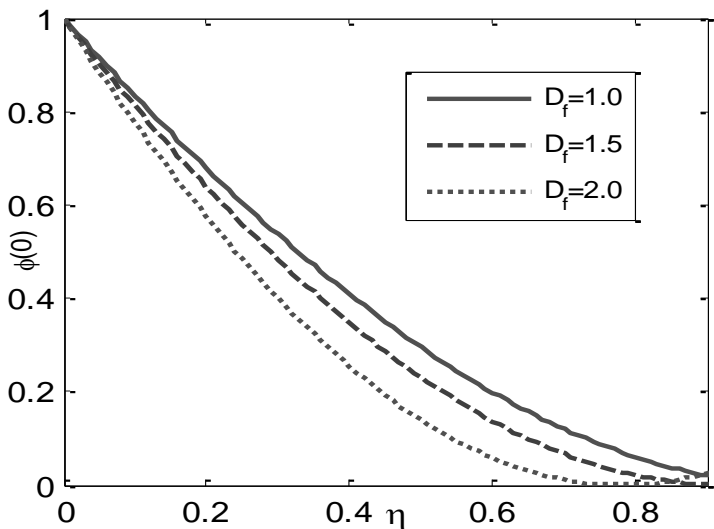

Fig.11. Concentration profile for various values of $\mathrm{D}_{\mathrm{f}}$ andM
$\mathrm{G}_{\mathrm{m}}=1.0, \mathrm{P}_{\mathrm{r}}=1.0, \mathrm{Q}=2.0, \mathrm{~S}=2.0, \gamma=60_{0}=1.0, \mathrm{~m}=1.0, \mathrm{~S}_{\mathrm{c}}=0.22$

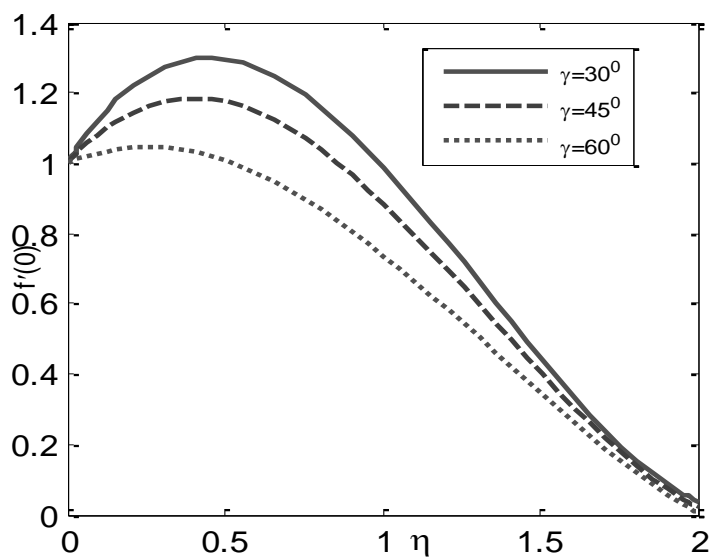

Fig.12. Primary velocity for various values of

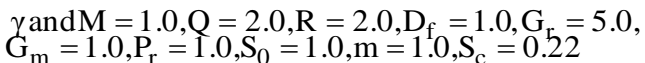




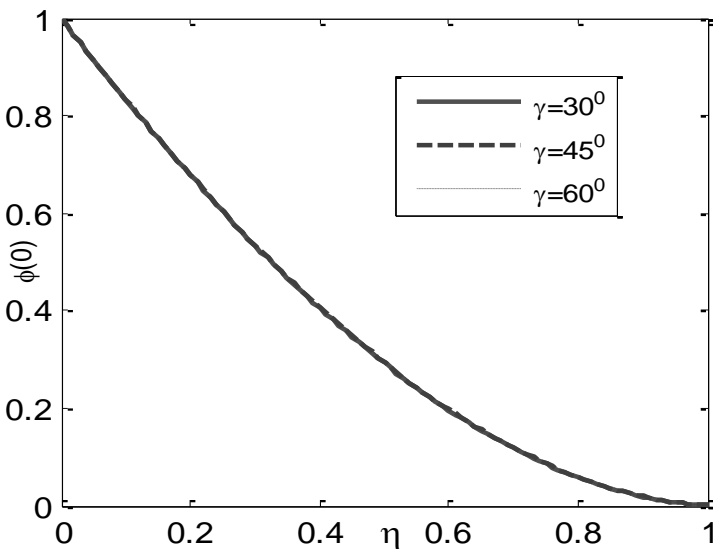

Fig.13. Concentration profile for various values of $\gamma$ and $\mathrm{M}=1.0, \mathrm{Q}=2.0, \mathrm{R}=2.0, \mathrm{D}_{\mathrm{f}}=1.0, \mathrm{G}_{\mathrm{r}}=5.0$,
$\mathrm{G}_{\mathrm{m}}=1.0, \mathrm{P}_{\mathrm{r}}=1.0, \mathrm{~S}_{0}=1.0, \mathrm{~m}=1.0, \mathrm{~S}_{\mathrm{c}}=0.22$

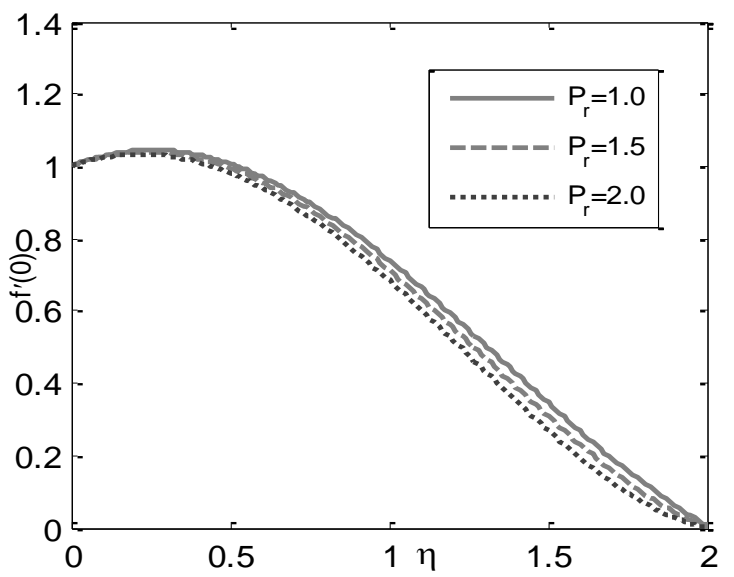

Fig.16. Primary velocity for various values of $\mathrm{P}_{\mathrm{r}}$ and $\mathrm{M}=1.0, \mathrm{Q}=2.0, \mathrm{R}=2.0, \mathrm{D}_{\mathrm{f}}=1.0, \mathrm{G}_{\mathrm{r}}=5.0$, $\mathrm{G}_{\mathrm{m}}=1.0, \gamma=60^{0}, \mathrm{~S}_{0}=1.0, \mathrm{~m}=1.0, \mathrm{~S}_{\mathrm{c}}=0.22$

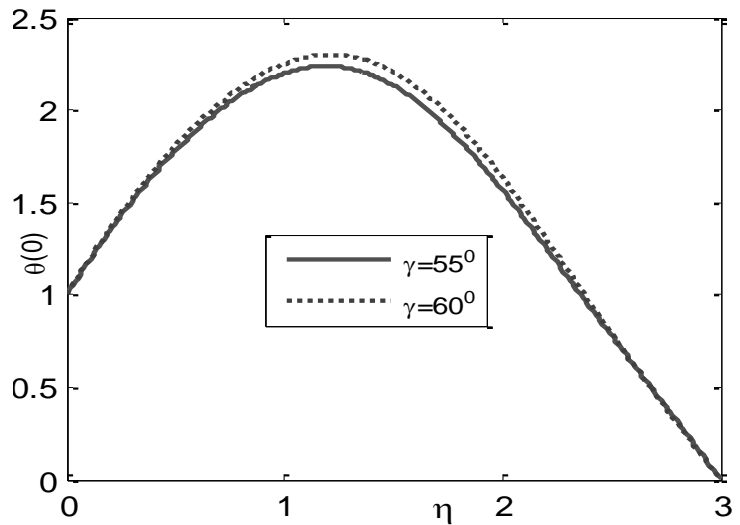

Fig.14. Temperature profile for various values of $\gamma$ and $\mathrm{M}=1.0, \mathrm{Q}=2.0, \mathrm{R}=2.0, \mathrm{D}_{\mathrm{f}}=1.0, \mathrm{G}_{\mathrm{r}}=5.0$,
$\mathrm{G}_{\mathrm{m}}=1.0, \mathrm{P}_{\mathrm{r}}=1.0, \mathrm{~S}_{0}=1.0, \mathrm{~m}=1.0, \mathrm{~S}_{\mathrm{c}}=0.22$

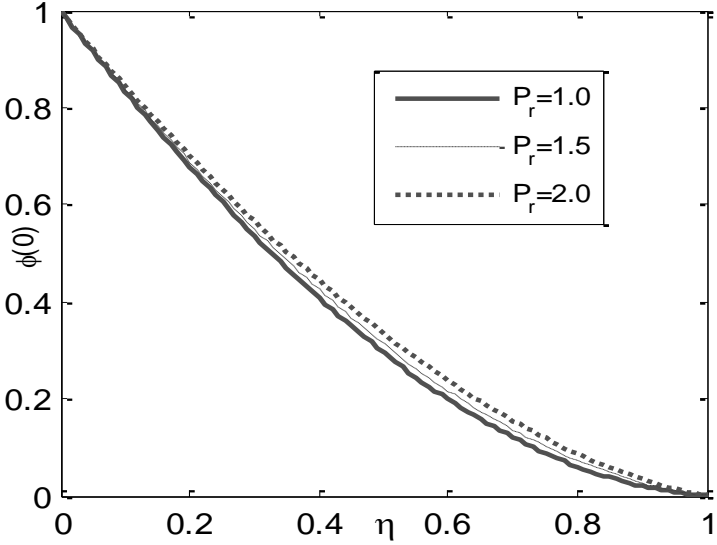

Fig.15. Concentration profile for various values of $\mathrm{P}_{\mathrm{r}}$ and $\mathrm{M}=1.0, \mathrm{Q}=2.0, \mathrm{R}=2.0, \mathrm{D}_{\mathrm{f}}=1.0, \mathrm{G}_{\mathrm{r}}=5.0$, $\mathrm{G}_{\mathrm{m}}=1.0, \gamma=60^{\circ}, \mathrm{S}_{0}=1.0, \mathrm{~m}=1.0, \mathrm{~S}_{\mathrm{c}}=0.22$

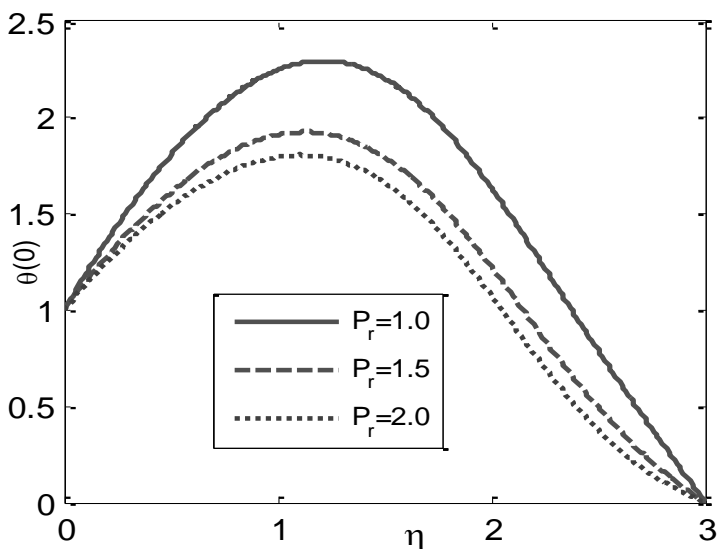

Fig.17. Temperature profile for various values of $\mathrm{P}_{\mathrm{r}}$ and $\mathrm{M}=1.0, \mathrm{Q}=2.0, \mathrm{R}=2.0, \mathrm{D}_{\mathrm{f}}=1.0, \mathrm{G}_{\mathrm{r}}=5.0$, $\mathrm{G}_{\mathrm{m}}=1.0, \gamma=60^{0}, \mathrm{~S}_{0}=1.0, \mathrm{~m}=1.0, \mathrm{~S}_{\mathrm{c}}=0.22$

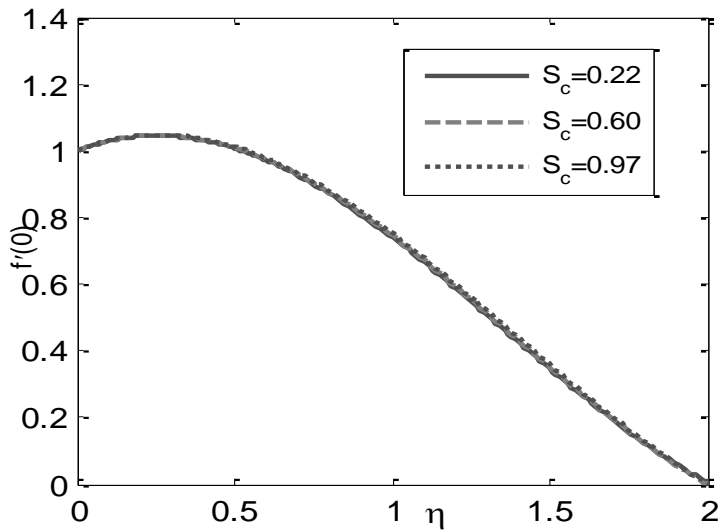

Fig.18. Primary velocity for various values of $\mathrm{S}_{\mathrm{c}}$ and $\mathrm{M}=1.0, \mathrm{Q}=2.0, \mathrm{R}=2.0, \mathrm{D}_{\mathrm{f}}=1.0, \mathrm{G}_{\mathrm{r}}=5.0$, $\mathrm{G}_{\mathrm{m}}=1.0, \gamma=60^{\circ}, \mathrm{S}_{0}=1.0, \mathrm{~m}=1.0, \mathrm{P}_{\mathrm{r}}=1.0$ 
IOSR Journal of Mathematics (IOSR-JM)

e-ISSN: 2278-5728, p-ISSN:2319-765X. Volume 9, Issue 4 (Jan. 2014), PP 33-45

www.iosrjournals.org

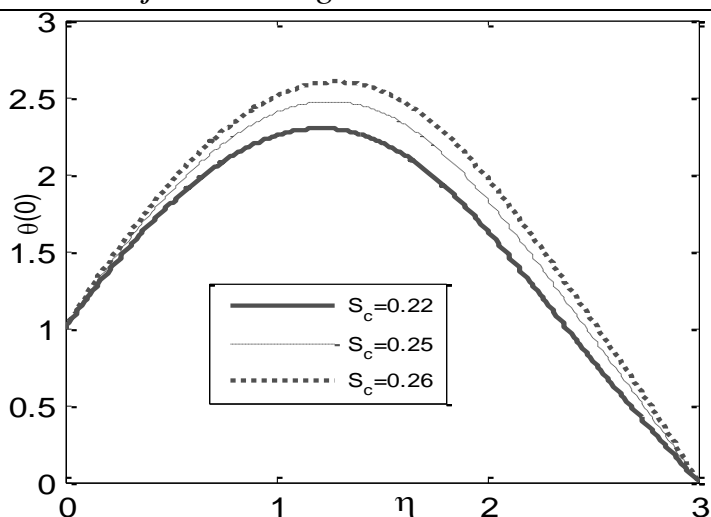

Fig.19. Temperature profile for various values of $\mathrm{S}_{\mathrm{c}}$ and $\mathrm{M}=1.0, \mathrm{Q}=2.0, \mathrm{R}=2.0, \mathrm{D}_{\mathrm{f}}=1.0, \mathrm{G}_{\mathrm{r}}=5.0$, $\mathrm{G}_{\mathrm{m}}=1.0, \gamma=60^{\circ}, \mathrm{S}_{0}=1.0, \mathrm{~m}=1.0, \mathrm{P}_{\mathrm{r}}=1.0$

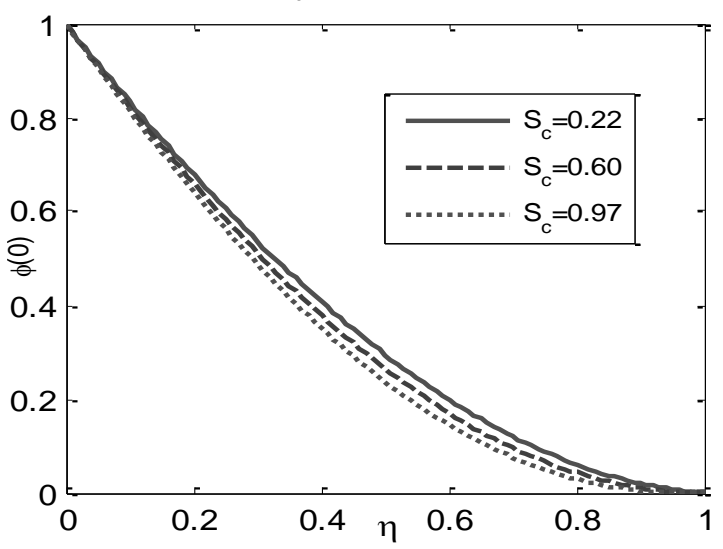

Fig.20. Concentration profile for various values of $\mathrm{S}_{\mathrm{c}}$ and $\mathrm{M}=1.0, \mathrm{Q}=2.0, \mathrm{R}=2.0, \mathrm{D}_{\mathrm{f}}=1.0, \mathrm{G}_{\mathrm{r}}=5.0$, $\mathrm{G}_{\mathrm{m}}=1.0, \gamma=60^{\circ}, \mathrm{S}_{0}=1.0, \mathrm{~m}=1.0, \mathrm{P}_{\mathrm{r}}=1.0$

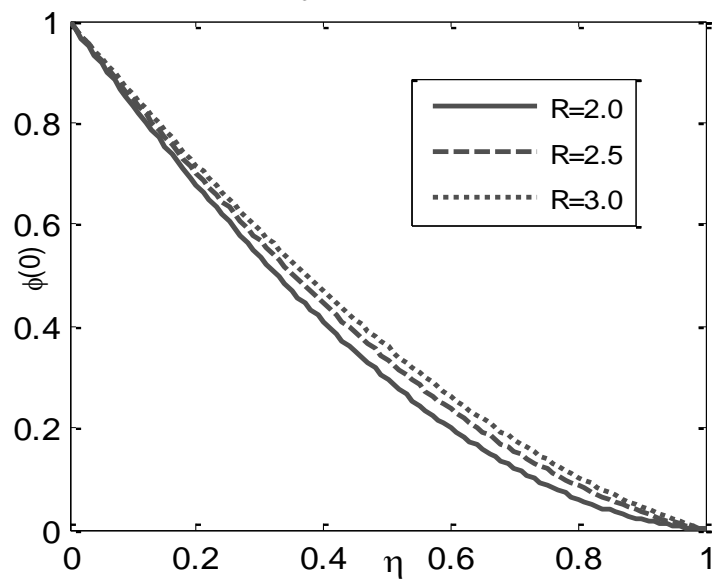

Fig.21. Concentration profile for various values of $\mathrm{R}$ and $\mathrm{M}=1.0, \mathrm{Q}=2.0, \mathrm{~S}_{\mathrm{c}}=0.22, \mathrm{D}_{\mathrm{f}}=1.0, \mathrm{G}_{\mathrm{r}}=5.0$, $\mathrm{G}_{\mathrm{m}}=1.0, \gamma=60^{\circ}, \mathrm{S}_{0}=1.0, \mathrm{~m}=1.0, \mathrm{P}_{\mathrm{r}}=1.0$

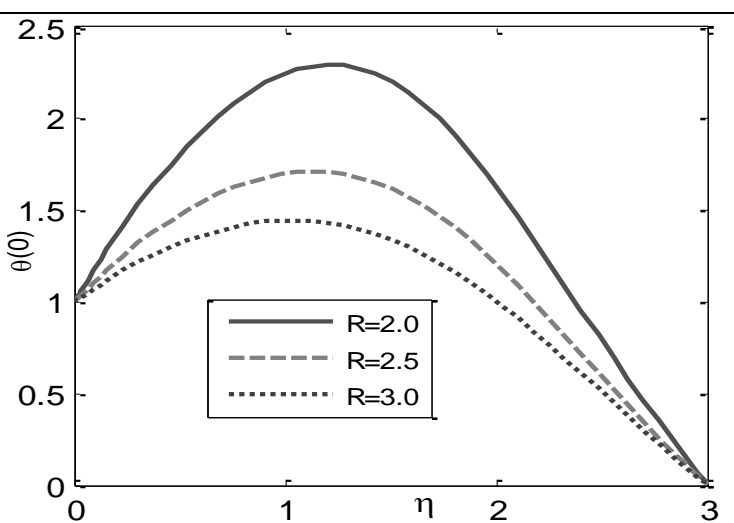

Fig.22. Temperature profile for various values of $\mathrm{R}$ and $\mathrm{M}=1.0, \mathrm{Q}=2.0, \mathrm{~S}_{\mathrm{c}}=0.22, \mathrm{D}_{\mathrm{f}}=1.0, \mathrm{G}_{\mathrm{r}}=5.0$, $\mathrm{G}_{\mathrm{m}}=1.0, \gamma=60^{\circ}, \mathrm{S}_{0}=1.0, \mathrm{~m}=1.0, \mathrm{P}_{\mathrm{r}}=1.0$

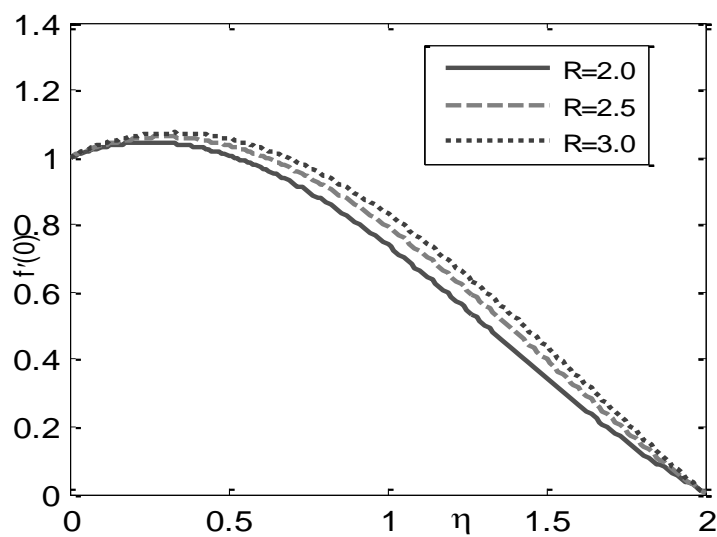

Fig.23. Primary velocity profile for various values of $\mathrm{R}$ and $\mathrm{M}=1.0, \mathrm{Q}=2.0, \mathrm{~S}_{\mathrm{c}}=0.22, \mathrm{D}_{\mathrm{f}}=1.0, \mathrm{G}_{\mathrm{r}}=5.0$, $\mathrm{G}_{\mathrm{m}}=1.0, \gamma=60^{0}, \mathrm{~S}_{0}=1.0, \mathrm{~m}=1.0, \mathrm{P}_{\mathrm{r}}=1.0$

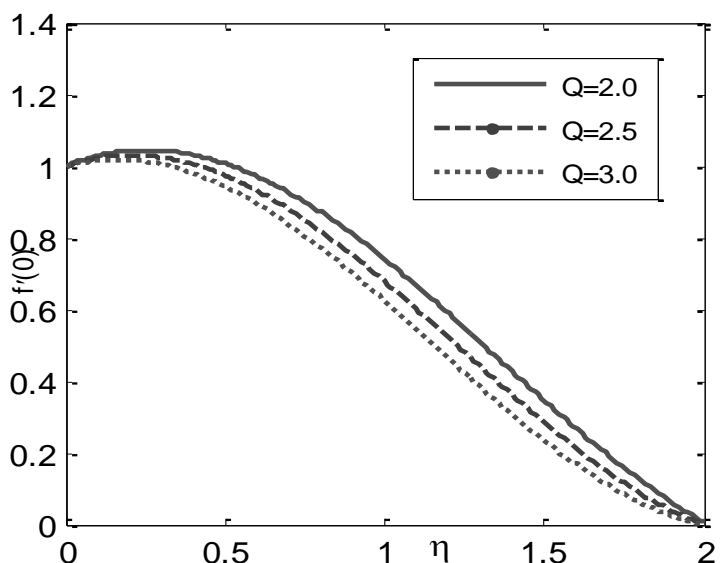

Fig.24. Primary velocity for various values of $\mathrm{Q}$ andm $=1.0, \mathrm{M}=1.0, \mathrm{R}=2.0, \gamma=60^{\circ}, \mathrm{G}_{\mathrm{r}}=5.0$,
$\mathrm{G}_{\mathrm{m}}=1.0, \mathrm{P}_{\mathrm{r}}=1.0, \mathrm{~S}_{0}=1.0, \mathrm{D}_{\mathrm{f}}=1.0, \mathrm{~S}_{\mathrm{c}}=0.22$ 


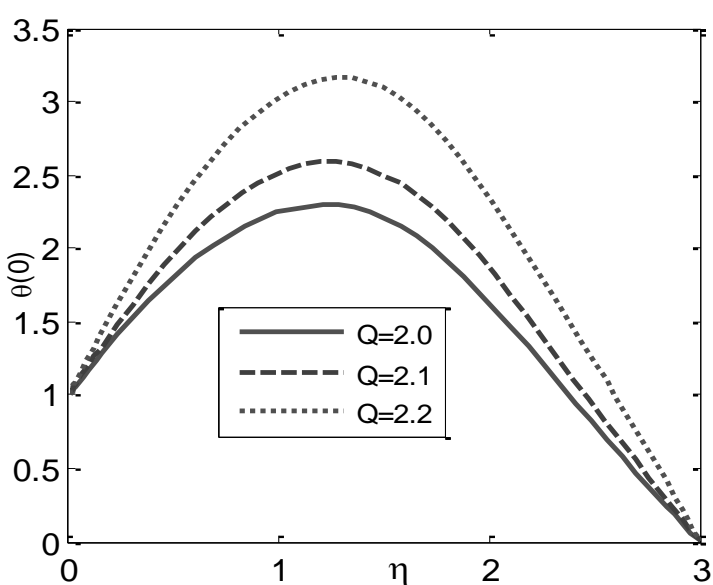

Fig.25. Temperature profile for various values of $\mathrm{Q}$ andm $=1.0, \mathrm{M}=1.0, \mathrm{R}=2.0, \gamma=60^{0}, \mathrm{G}_{\mathrm{r}}=5.0$,
$\mathrm{G}_{\mathrm{m}}=1.0, \mathrm{P}_{\mathrm{r}}=1.0, \mathrm{~S}_{0}=1.0, \mathrm{D}_{\mathrm{f}}=1.0, \mathrm{~S}_{\mathrm{c}}=0.22$

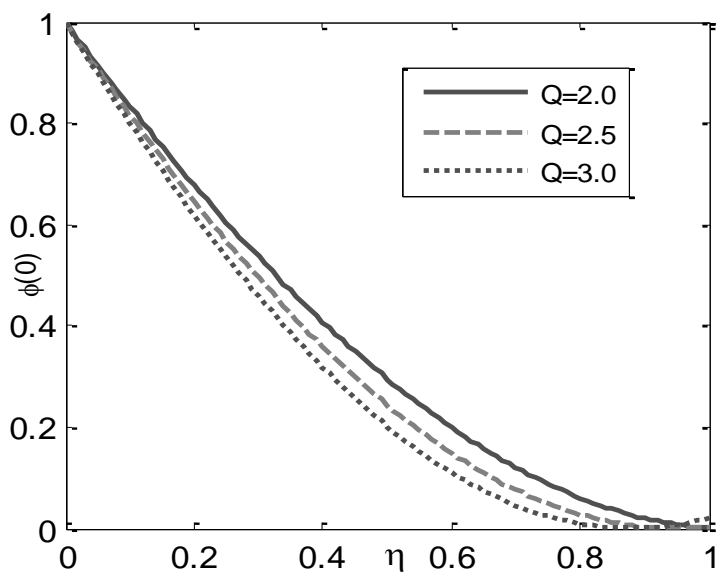

Fig.26. Concentration profile for various values of $\mathrm{Q}$ andm $=1.0, \mathrm{M}=1.0, \mathrm{R}=2.0, \gamma=60^{\circ}, \mathrm{G}_{\mathrm{r}}=5.0$,
$\mathrm{G}_{\mathrm{m}}=1.0, \mathrm{P}_{\mathrm{r}}=1.0, \mathrm{~S}_{0}=1.0, \mathrm{D}_{\mathrm{f}}=1.0, \mathrm{~S}_{\mathrm{c}}=0.22$

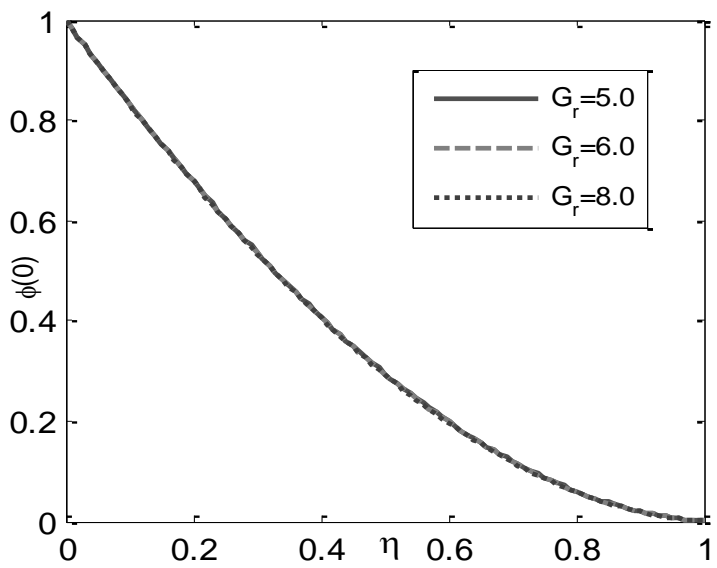

Fig.27. Concentration profile for various values of $\mathrm{G}_{r}$ and $\mathrm{M}=1.0, \mathrm{Q}=2.0, \mathrm{R}=2.0, \mathrm{D}_{\mathrm{f}}=1.0, \mathrm{~S}_{\mathrm{c}}=.22$, $\mathrm{G}_{\mathrm{m}}=1.0, \gamma=60^{\circ}, \mathrm{S}_{0}=1.0, \mathrm{~m}=1.0, \mathrm{P}_{\mathrm{r}}=1.0$

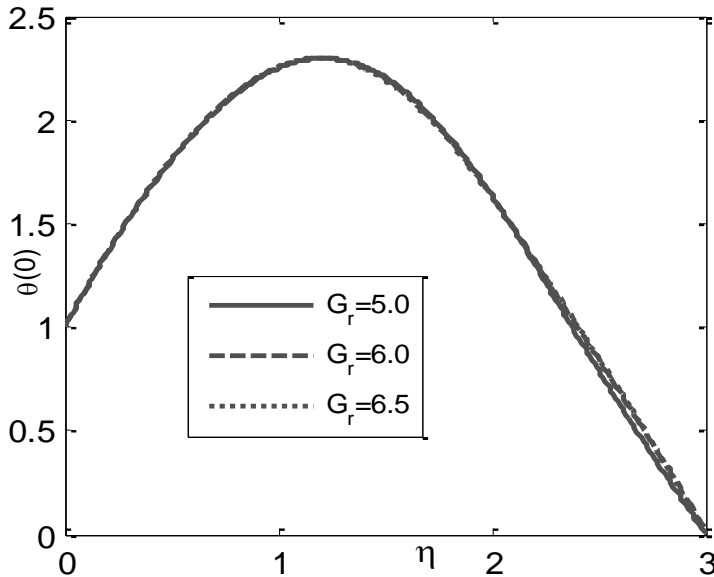

Fig.28. Temperature profile for various values of $\mathrm{G}_{r}$ and $\mathrm{M}=1.0, \mathrm{Q}=2.0, \mathrm{R}=2.0, \mathrm{D}_{\mathrm{f}}=1.0, \mathrm{~S}_{\mathrm{c}}=.22$, $\mathrm{G}_{\mathrm{m}}=1.0, \gamma=60^{\circ}, \mathrm{S}_{0}=1.0, \mathrm{~m}=1.0, \mathrm{P}_{\mathrm{r}}=1.0$

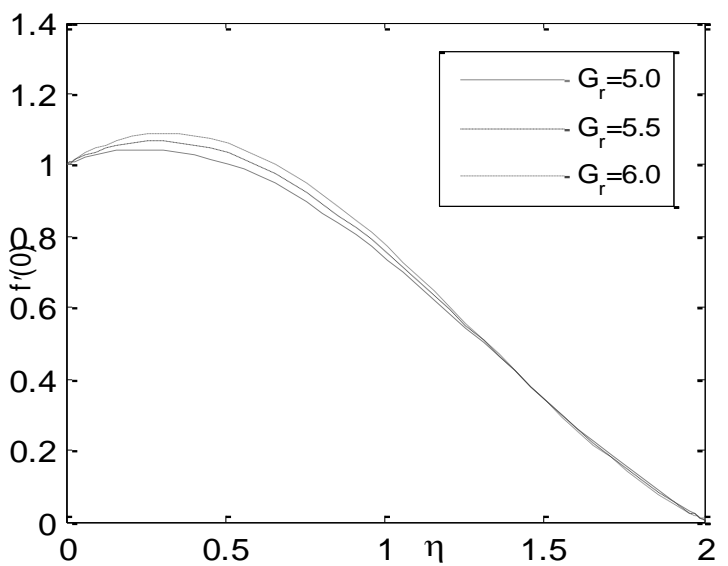

Fig.29. Primary velocity for various values of $\mathrm{G}_{r}$ and $\mathrm{M}=1.0, \mathrm{Q}=2.0, \mathrm{R}=2.0, \mathrm{D}_{\mathrm{f}}=1.0, \mathrm{~S}_{\mathrm{c}}=.22$, $\mathrm{G}_{\mathrm{m}}=1.0, \gamma=60^{\circ}, \mathrm{S}_{0}=1.0, \mathrm{~m}=1.0, \mathrm{P}_{\mathrm{r}}=1.0$

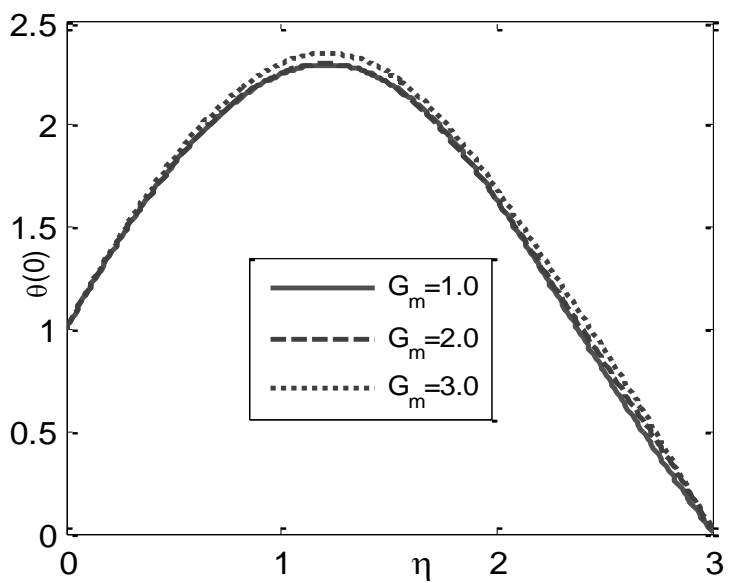

Fig.30. Temperature profile for various values of $\mathrm{G}_{m}$ and $\mathrm{M}=1.0, \mathrm{Q}=2.0, \mathrm{R}=2.0, \mathrm{D}_{\mathrm{f}}=1.0, \mathrm{~S}_{\mathrm{c}}=.22$, $\mathrm{G}_{\mathrm{r}}=5.0, \gamma=60^{0}, \mathrm{~S}_{0}=1.0, \mathrm{~m}=1.0, \mathrm{P}_{\mathrm{r}}=1.0$ 


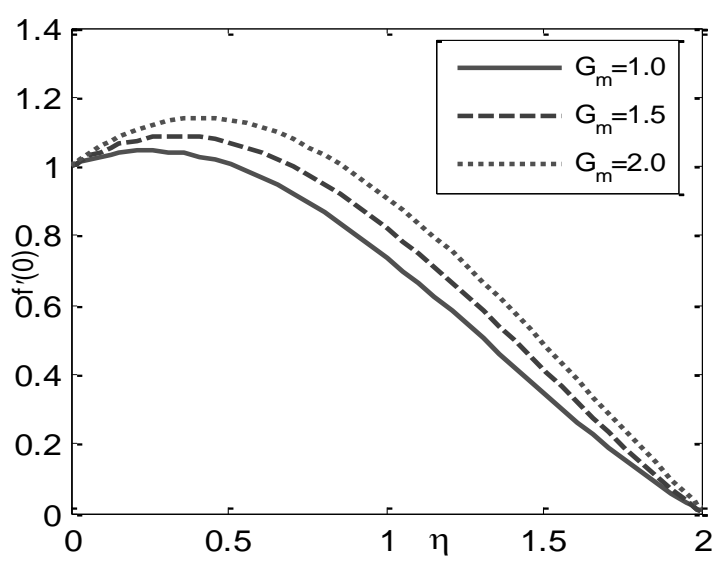

Fig.31. Primary velocity for various values of $\mathrm{G}_{m}$ and $\mathrm{M}=1.0 \mathrm{Q}=2.0, \mathrm{R}=2.0, \mathrm{D}_{\mathrm{f}}=1.0, \mathrm{~S}_{\mathrm{c}}=.22$, $\mathrm{G}_{\mathrm{r}}=5.0, \gamma=60^{\circ}, \mathrm{S}_{0}=1.0, \mathrm{~m}=1.0, \mathrm{P}_{\mathrm{r}}=1.0$

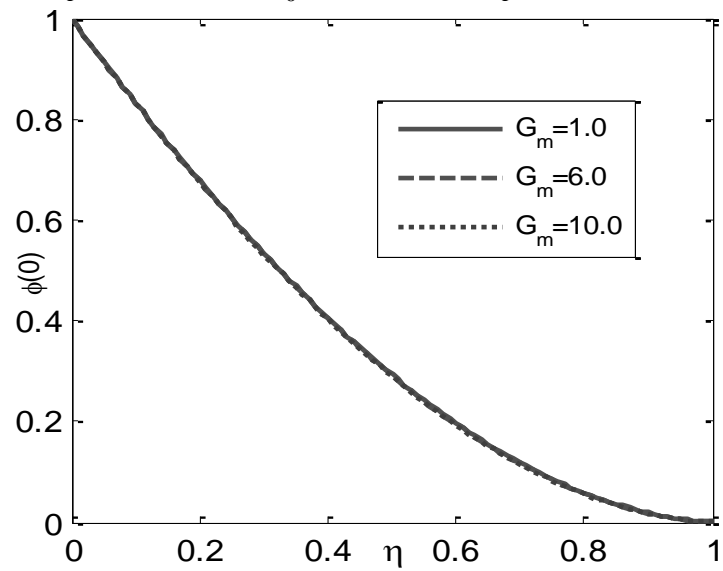

Fig.32. Concentration profile for various values of $\mathrm{G}_{m}$ and $\mathrm{M}=1.0 \mathrm{Q}=2.0, \mathrm{R}=2.0, \mathrm{D}_{\mathrm{f}}=1.0, \mathrm{~S}_{\mathrm{c}}=.22$, $\mathrm{G}_{\mathrm{r}}=5.0, \gamma=60^{\circ}, \mathrm{S}_{0}=1.0, \mathrm{~m}=1.0, \mathrm{P}_{\mathrm{r}}=1.0$

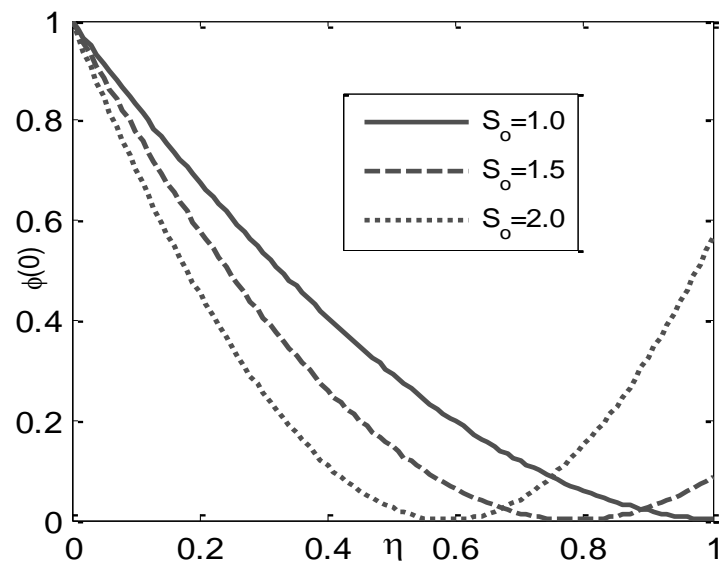

Fig.33. Concentration profile for various values of $S_{o}$ and $=1.0, \mathrm{Q}=2.0, \mathrm{R}=2.0, \mathrm{D}_{\mathrm{f}}=1.0, \mathrm{~S}_{\mathrm{c}}=.22$, $\mathrm{G}_{\mathrm{r}}=5.0, \gamma=60^{0}, \mathrm{G}_{\mathrm{m}}=1.0, \mathrm{~m}=1.0, \mathrm{P}_{\mathrm{r}}=1.0$

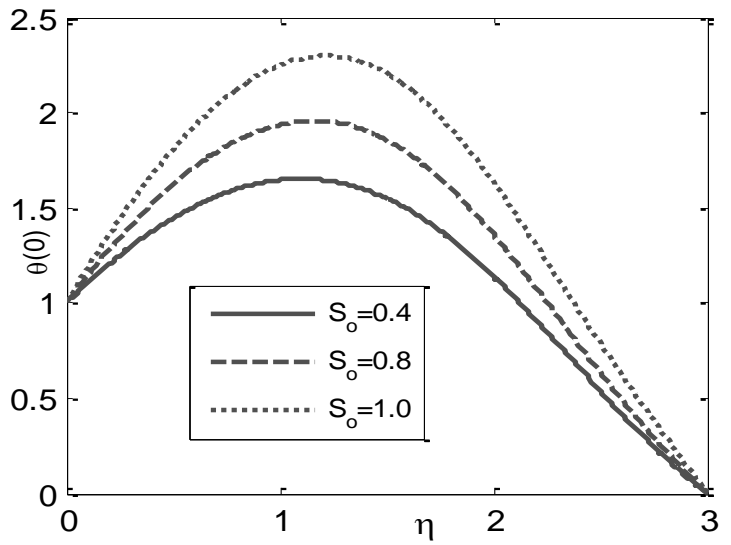

Fig.34. Temperature profile for various values of $S_{o}$ and $\mathrm{M}=1.0, \mathrm{Q}=2.0, \mathrm{R}=2.0, \mathrm{D}_{\mathrm{f}}=1.0, \mathrm{~S}_{\mathrm{c}}=.22$, $\mathrm{G}_{\mathrm{r}}=5.0, \gamma=60^{\circ}, \mathrm{G}_{\mathrm{m}}=1.0, \mathrm{~m}=1.0, \mathrm{P}_{\mathrm{r}}=1.0$

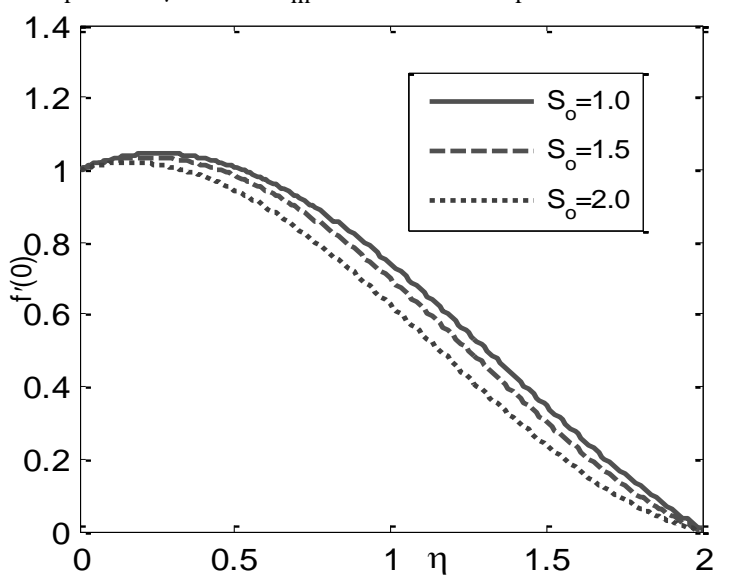

Fig.35. Primary velocity for various values of $S_{o}$ andM $=1.0, \mathrm{Q}=2.0, \mathrm{R}=2.0, \mathrm{D}_{\mathrm{f}}=1.0, \mathrm{~S}_{\mathrm{c}}=.22$, $\mathrm{G}_{\mathrm{r}}=5.0, \gamma=60^{\circ}, \mathrm{G}_{\mathrm{m}}=1.0, \mathrm{~m}=1.0, \mathrm{P}_{\mathrm{r}}=1.0$ 
Table-1: The skin friction coefficient at the wall, for various values of

$\mathrm{M}, \mathrm{m}, \gamma, \mathrm{P}_{\mathrm{r},} \mathrm{S}_{\mathrm{c}}, \mathrm{R}$ and taking $\mathrm{G}_{\mathrm{r}}=5.0, \mathrm{G}_{\mathrm{m}}=1.0, \mathrm{~S}_{0}=1.0, \mathrm{D}_{\mathrm{f}}=1.0, \mathrm{Q}=2.0$

\begin{tabular}{|l|l|l|l|l|l|l|}
\hline $\mathbf{M}$ & $\mathbf{m}$ & $\mathbf{R}$ & $\gamma$ & $\mathbf{P}_{\mathbf{r}}$ & $\mathbf{S}_{\mathbf{c}}$ & $\mathrm{f}^{\prime \prime}(0)$ \\
\hline $\mathbf{1 . 0}$ & 1.0 & 2.0 & $60^{0}$ & 1.0 & 0.22 & 0.3608 \\
\hline $\mathbf{2 . 5}$ & 1.0 & 2.0 & $60^{0}$ & 1.0 & 0.22 & 0.1600 \\
\hline $\mathbf{3 . 0}$ & 1.0 & 2.0 & $60^{0}$ & 1.0 & 0.22 & 0.1300 \\
\hline 1.0 & $\mathbf{1 . 0}$ & 2.0 & $60^{0}$ & 1.0 & 0.22 & 0.3608 \\
\hline 1.0 & $\mathbf{1 . 5}$ & 2.0 & $60^{0}$ & 1.0 & 0.22 & 0.4600 \\
\hline 1.0 & $\mathbf{2 . 0}$ & 2.0 & $60^{0}$ & 1.0 & 0.22 & 0.5092 \\
\hline 1.0 & 1.0 & $\mathbf{2 . 0}$ & $60^{0}$ & 1.0 & 0.22 & 0.3608 \\
\hline 1.0 & 1.0 & $\mathbf{2 . 5}$ & $60^{0}$ & 1.0 & 0.22 & 0.4168 \\
\hline 1.0 & 1.0 & $\mathbf{3 . 0}$ & $60^{0}$ & 1.0 & 0.22 & 0.4554 \\
\hline 1.0 & 1.0 & 2.0 & $60^{0}$ & 1.0 & 0.22 & 1.4209 \\
\hline 1.0 & 1.0 & 2.0 & $45^{0}$ & 1.0 & 0.22 & 0.9708 \\
\hline 1.0 & 1.0 & 2.0 & $\mathbf{6 0}^{0}$ & 1.0 & 0.22 & 0.3608 \\
\hline 1.0 & 1.0 & 2.0 & $60^{0}$ & $\mathbf{1 . 0}$ & 0.22 & 0.3608 \\
\hline 1.0 & 1.0 & 2.0 & $60^{0}$ & $\mathbf{1 . 5}$ & 0.22 & 0.3378 \\
\hline 1.0 & 1.0 & 2.0 & $60^{0}$ & $\mathbf{2 . 0}$ & 0.22 & 0.3138 \\
\hline 1.0 & 1.0 & 2.0 & $60^{0}$ & 1.0 & $\mathbf{0 . 2 2}$ & 0.3608 \\
\hline 1.0 & 1.0 & 2.0 & $60^{0}$ & 1.0 & $\mathbf{0 . 6 0}$ & 0.3649 \\
\hline 1.0 & 1.0 & 2.0 & $60^{0}$ & 1.0 & $\mathbf{0 . 9 7}$ & 0.3700 \\
\hline
\end{tabular}

Table-2: The local Nusselt number, $\theta^{\prime}(0)$, for various values of

$\mathrm{M}, \mathrm{m}, \gamma, \mathrm{P}_{\mathrm{r}, \mathrm{S}_{\mathrm{c}}}, \mathrm{R}$ and taking $\mathrm{G}_{\mathrm{r}}=5.0, \mathrm{G}_{\mathrm{m}}=1.0, \mathrm{~S}_{0}=1.0, \mathrm{D}_{\mathrm{f}}=1.0, \mathrm{Q}=2.0$.

\begin{tabular}{|c|c|c|c|c|c|c|}
\hline M & $\mathbf{m}$ & $\mathbf{R}$ & $\gamma$ & $\mathbf{P}_{\mathbf{r}}$ & $\mathbf{S}_{\mathrm{c}}$ & $\theta^{\prime}(0)$ \\
\hline 1.0 & 1.0 & 2.0 & $60^{\circ}$ & 1.0 & 0.22 & 1.9009 \\
\hline 1.5 & 1.0 & 2.0 & $60^{\circ}$ & 1.0 & 0.22 & 1.9152 \\
\hline 2.0 & 1.0 & 2.0 & $60^{\circ}$ & 1.0 & 0.22 & 1.9396 \\
\hline 1.0 & 1.0 & 2.0 & $60^{\circ}$ & 1.0 & 0.22 & 1.9009 \\
\hline 1.0 & 3.0 & 2.0 & $60^{\circ}$ & 1.0 & 0.22 & 1.8823 \\
\hline 1.0 & 5.0 & 2.0 & $60^{\circ}$ & 1.0 & 0.22 & 1.8811 \\
\hline 1.0 & 1.0 & 2.0 & $60^{\circ}$ & 1.0 & 0.22 & 1.9009 \\
\hline 1.0 & 1.0 & 2.5 & $60^{\circ}$ & 1.0 & 0.22 & 1.7143 \\
\hline 1.0 & 1.0 & 3.0 & $60^{\circ}$ & 1.0 & 0.22 & 0.8185 \\
\hline 1.0 & 1.0 & 2.0 & $30^{0}$ & 1.0 & 0.22 & - \\
\hline 1.0 & 1.0 & 2.0 & $55^{0}$ & 1.0 & 0.22 & 1.8480 \\
\hline 1.0 & 1.0 & 2.0 & $60^{\circ}$ & 1.0 & 0.22 & 1.9009 \\
\hline 1.0 & 1.0 & 2.0 & $60^{\circ}$ & 1.0 & 0.22 & 1.9009 \\
\hline 1.0 & 1.0 & 2.0 & $60^{\circ}$ & 1.5 & 0.22 & 1.4890 \\
\hline 1.0 & 1.0 & 2.0 & $60^{\circ}$ & 2.0 & 0.22 & 1.3320 \\
\hline 1.0 & 1.0 & 2.0 & $60^{\circ}$ & 1.0 & 0.22 & 1.9009 \\
\hline 1.0 & 1.0 & 2.0 & $60^{\circ}$ & 1.0 & 0.25 & 2.0621 \\
\hline 1.0 & 1.0 & 2.0 & $60^{\circ}$ & 1.0 & 0.26 & 2.1801 \\
\hline
\end{tabular}

Table-3: The local Sherwood number, $-\varphi^{\prime}(0)$, for various values of

$\mathrm{M}, \mathrm{m}, \gamma, \mathrm{P}_{\mathrm{r}} \mathrm{S}_{\mathrm{c}}, \mathrm{R}$ and taking $\mathrm{G}_{\mathrm{r}}=5.0, \mathrm{G}_{\mathrm{m}}=1.0, \mathrm{~S}_{0}=1.0, \mathrm{D}_{\mathrm{f}}=1.0, \mathrm{Q}=2.0$.

\begin{tabular}{|c|c|c|c|c|c|c|}
\hline $\mathbf{M}$ & $\mathbf{m}$ & $\mathbf{R}$ & $\gamma$ & $\mathbf{P}_{\mathbf{r}}$ & $\mathbf{S}_{\mathrm{c}}$ & $-\varphi^{\prime}(0)$ \\
\hline 1.0 & 1.0 & 2.0 & $60^{0}$ & 1.0 & 0.22 & 1.7190 \\
\hline 2.0 & 1.0 & 2.0 & $60^{0}$ & 1.0 & 0.22 & 1.7178 \\
\hline 3.0 & 1.0 & 2.0 & $60^{0}$ & 1.0 & 0.22 & 1.7166 \\
\hline 1.0 & 1.0 & 2.0 & $60^{\circ}$ & 1.0 & 0.22 & 1.7190 \\
\hline 1.0 & 3.0 & 2.0 & $60^{0}$ & 1.0 & 0.22 & 1.7190 \\
\hline 1.0 & 5.0 & 2.0 & $60^{\circ}$ & 1.0 & 0.22 & 1.7190 \\
\hline 1.0 & 1.0 & 2.0 & $60^{0}$ & 1.0 & 0.22 & 1.7190 \\
\hline 1.0 & 1.0 & 2.5 & $60^{\circ}$ & 1.0 & 0.22 & 1.5820 \\
\hline 1.0 & 1.0 & 3.0 & $60^{0}$ & 1.0 & 0.22 & 1.4908 \\
\hline 1.0 & 1.0 & 2.0 & $30^{0}$ & 1.0 & 0.22 & 1.7246 \\
\hline 1.0 & 1.0 & 2.0 & $45^{0}$ & 1.0 & 0.22 & 1.7222 \\
\hline 1.0 & 1.0 & 2.0 & $60^{0}$ & 1.0 & 0.22 & 1.7190 \\
\hline 1.0 & 1.0 & 2.0 & $60^{0}$ & 1.0 & 0.22 & 1.7190 \\
\hline 1.0 & 1.0 & 2.0 & $60^{0}$ & 1.5 & 0.22 & 1.6641 \\
\hline 1.0 & 1.0 & 2.0 & $60^{\circ}$ & 2.0 & 0.22 & 1.6044 \\
\hline 1.0 & 1.0 & 2.0 & $60^{0}$ & 1.0 & 0.22 & 1.7190 \\
\hline 1.0 & 1.0 & 2.0 & $60^{\circ}$ & 1.0 & 0.60 & 1.8169 \\
\hline 1.0 & 1.0 & 2.0 & $60^{\circ}$ & 1.0 & 0.97 & 1.9106 \\
\hline
\end{tabular}




\section{NOMENCLATURE}

\begin{tabular}{|c|c|}
\hline MHD & Magnetohydrodynamics \\
\hline$c_{p}$ & Specific heat of with constant pressure \\
\hline $\mathrm{g}$ & Gravitational acceleration \\
\hline 90 & Secondary velocity \\
\hline$f^{\prime}$ & Velocity profile \\
\hline M & Magnetic parameter, $M=\frac{\sigma B_{0}^{2}}{\rho b^{2}}$ \\
\hline $\mathrm{m}$ & Hall parameter, $m=\omega_{\mathrm{e}} \tau_{\mathrm{e}}$ \\
\hline$v$ & Kinematic viscosity \\
\hline$\eta$ & Similarity variable \\
\hline$\alpha$ & Thermal diffusivity, $\alpha=\frac{\mathrm{k}}{\rho \mathrm{c}_{\mathrm{p}}}$ \\
\hline$\beta$ & Thermal expansion coefficient \\
\hline$\beta^{*}$ & Coefficient of expansion with concentration \\
\hline$\rho$ & Density \\
\hline$\sigma$ & Fluid electrical conductivity \\
\hline$\theta$ & Dimensionless temperature \\
\hline $\mathrm{u}$ & Velocity component in $\mathrm{x}$-direction \\
\hline $\mathrm{v}$ & Velocity component in y-direction \\
\hline w & Secondary Velocity \\
\hline $\mathrm{T}$ & Temperature \\
\hline $\mathrm{k}_{\mathrm{T}}$ & Coefficient of concentration \\
\hline $\mathrm{D}_{\mathrm{m}}$ & Thermal molecular diffusivity \\
\hline $\mathrm{C}_{\mathrm{s}}$ & Concentration susceptibility \\
\hline$C_{\mathrm{cx}}$ & $\begin{array}{l}\text { Concentration of the fluid outside the boundary } \\
\text { layer }\end{array}$ \\
\hline$P_{Y}$ & Prandle number, $\mathrm{P}_{\mathrm{r}}=\frac{\mu \mathrm{c}_{\mathrm{p}}}{\mathrm{k}}$ \\
\hline$G_{Y}$ & $\begin{array}{l}\text { Local thermal Grashof number, } \\
\qquad \mathrm{G}_{\mathrm{r}}=\frac{\mathrm{g} \beta\left(\mathrm{T}_{\mathrm{w}}-\mathrm{T}_{\infty}\right)}{b^{2} x}\end{array}$ \\
\hline$G_{m}$ & $\begin{array}{l}\text { Local solutal Grashof number } \\
\mathrm{G}_{\mathrm{m}}=\frac{\mathrm{g} \beta^{*}\left(\mathrm{C}_{\mathrm{w}}-C_{\infty}\right)}{\mathrm{b}^{2} x}\end{array}$ \\
\hline$S_{c}$ & Schmidt number, $\mathrm{S}_{\mathrm{c}}=\frac{\mathrm{v}}{\mathrm{D}_{\mathrm{m}}}$ \\
\hline $\mathrm{D}_{\mathrm{f}}$ & Dufour number, $\mathrm{D}_{\mathrm{f}}=\frac{\mathrm{D}_{\mathrm{m}} \mathrm{k}_{\mathrm{T}} \rho\left(\mathrm{C}_{\mathrm{w}}-\mathrm{C}_{\infty}\right)}{\mathrm{c}_{\mathrm{s}} \mathrm{k}\left(\mathrm{T}_{\mathrm{w}}-\mathrm{T}_{\infty}\right)}$ \\
\hline $\begin{array}{l}\mathbf{J} \\
\mathrm{f}^{\prime \prime}(0)\end{array}$ & $\begin{array}{l}\text { Current density } \\
\text { Skin friction }\end{array}$ \\
\hline$\theta^{\prime}(0)$ & Rate of temperature \\
\hline$\varphi^{\prime}(0)$ & Rate of concentration \\
\hline$\omega_{\mathrm{e}}$ & Electron frequency \\
\hline $\mathrm{p}_{\mathrm{e}}$ & Electron pressure \\
\hline $\mathrm{n}_{\mathrm{e}}$ & Number of electro density \\
\hline$\tau_{\mathrm{e}}$ & Electron collision time \\
\hline $\mathrm{q}_{\mathrm{r}}$ & Radiative heat flux \\
\hline$\sigma^{*}$ & Stefan-Boltzmann constant \\
\hline $\mathrm{e}$ & Electron \\
\hline B & Magnetic field \\
\hline $\mathrm{R}$ & Radiation parameter, $\mathrm{R}=\frac{16 \sigma^{*} \mathrm{~T}_{\infty}^{3}}{3 \mathrm{kk}^{*}}$ \\
\hline
\end{tabular}




\begin{tabular}{|ll|}
\hline $\mathrm{Q}$ & Heat generation, $\mathrm{Q}=\frac{\mathrm{Q}_{0}}{\mathrm{~kb}}$ \\
$\mathrm{~S}_{0}$ & Soret number, $\mathrm{S}_{0}=\frac{\mathrm{k}_{\mathrm{T}}\left(\mathrm{T}_{\mathrm{w}}-\mathrm{T}_{\infty}\right)}{\mathrm{T}_{\mathrm{m}}\left(\mathrm{C}_{\mathrm{w}}-\mathrm{C}_{\infty}\right)}$ \\
$B_{0}$ & Constant magnetic field intensity \\
$\mathrm{U}_{0}$ & Constant velocity \\
$T_{w}$ & Temperature at the Plate \\
$\mathrm{T}_{\mathrm{m}}$ & Mean fluid temperature \\
$T_{\infty}$ & Temperature of the fluid outside the boundary \\
$\mathrm{k}^{*}$ & layer \\
Subscript & Mean absorption coefficient \\
$\mathrm{w}$ & Quantities at wall \\
$\infty$ & Quantities at the free stream \\
\hline
\end{tabular}

\section{REFERENCES}

[1] E.M.A. Elbashbeshy, M.A.A. Bazid, Heat transfer over an unsteady stretching surface, Heat Mass Transfer 41, 2004, 1-4.

[2] Saleh M. Alharbi1, Mohamed A. A. Bazid2, Mahmoud S. El Gendy, heat and mass transfer in MHD visco-elastic fluid flow through a porous medium over a stretching sheet with chemical reaction, Applied Mathematics, 1, 2010, 446-455.

[3] M. A. Seddeek and M. S. Abdelmeguid, "Effects of Radiation and Thermal Diffusivity on Heat Transfer over a Stretching Surface with Variable Heat Flux," Physics Letters A, Vol. 348, No. 3 6, January 2006, pp. 172-179.

[4] A. A. Afify, "Similarity Solution in MHD: Effects of Thermal Diffusion and Diffusion Thermo on Free Convective Heat and Mass Transfer over a Stretching Surface Considering Suction or Injection," Communications in Nonlinear Science and Numerical Simulation, Vol. 14, No. 5, May 2009, pp. 2202-2214.

[5] Akiyama M, and Chong,, Numerical heat transfer Part A:,32 (1997) 419-33.

[6] Sudha Mathew, P. Raveendra Nath and N. B. V. Rama Deva Prasad, : Hall Effects On Heat and Mass Transfer Through a Porous Medium In a Rotating Channel With Radiation, Advances in Applied Science Research, 3 (5), 2012, 3004-3019.

[7] R. Kumar and K. D. Singh,: Mathematical modeling of soret and hall effects on oscillatory MHD free convective flow of radiating fluid in a rotating vertical porous channel filled with porous medium, Int. J. of Appl. Math and Mech. 8 (6), 2012, 49-68.

[8] L.J. Grubka, K.M. Bobba, Heat transfer characteristics of a continuous stretching surface with variable temperature, ASME J. Heat Transfer 107, 1985, 248-250.

[9] C.H. Chen, Laminar mixed convection adjacent to vertical, continuously stretching sheets, Heat Mass Transfer 33, 1998, 471-476. 